\title{
Effect of Processing Conditions on Microstructure and Thermal Conductivity of Hot-Extruded Aluminum/Graphite Composites
}

\author{
Li-Fu Yi, Noriaki Yoshida, Tetsuhiko Onda and Zhong-Chun Chen* \\ Department of Mechanical and Aerospace Engineering, Graduate School of Engineering, Tottori University, Tottori 680-8552, Japan
}

\begin{abstract}
Aluminum/graphite composites have been successfully prepared by a hot-extrusion technique. The effects of processing conditions such as graphite particle size, graphite content, and extrusion temperature on extrusion behavior, microstructure, texture, and thermal conductivity have been systematically investigated. During the hot extrusion, the graphite was subjected to deformation and hence distributed along the extrusion direction in the extruded $\mathrm{Al} /$ graphite composites. The $(00 l)$ basal planes of the graphite were preferentially orientated along the extrusion direction. The preferred orientation of the graphite resulted in an anisotropy of thermal conductivity in the extruded samples. On the other hand, the utilization of bimodal graphite powder consisting of coarse and fine particles is beneficial to the enhancement of both relative density and thermal conductivity. Moreover, when a pressed green compact was rotated $90^{\circ}$ and then subjected to the hot extrusion, the resulting composite exhibited higher thermal conductivity due to its higher density, fewer $\mathrm{Al} /$ graphite interfaces, and higher orientation degree of the graphite. [doi:10.2320/matertrans.M2018220]
\end{abstract}

(Received July 5, 2018; Accepted October 29, 2018; Published December 7, 2018)

Keywords: hot extrusion, aluminum-matrix composites, graphite flakes, microstructure, thermal conductivity

\section{Introduction}

Concurrent with the increase of power density in various electronic devices, the generation of large amount of heat has become a serious issue in the fields of electronic packaging and thermal management applications. ${ }^{1)}$ In order to enhance the efficiency and service life of these electronic devices, it is important to develop efficient heat-dissipation materials to meet the requirements of rapid heat removal. ${ }^{2)}$

Among various material systems, metal-matrix composites are of particular interest for heat-dissipation materials. ${ }^{3)}$ Aluminum (Al), as a matrix material, has been extensively used due to its high thermal conductivity (TC), lightweight and low cost. The common second phases for Al-matrix composites mainly include $\mathrm{SiC}$, diamond, graphite, carbon fibers including carbon nanotubes (CNTs) and nanofibers (CNFs), and so on. It has been reported that $\mathrm{Al} / \mathrm{SiC}$ composites exhibit a TC value of $\sim 200 \mathrm{~W} / \mathrm{mK},{ }^{4)}$ but it is still insufficient for many thermal applications. The TC of $\mathrm{Al} /$ diamond composites can reach a level of 400-550 $\mathrm{W} / \mathrm{mK}^{5)}$ but the high cost of diamond seriously limits their industrial applications. $\mathrm{Al} /$ carbon fibers composites show unsatisfied TC values of $150-220 \mathrm{~W} / \mathrm{mK}$, which is mainly attributed to the difficulties in orientation control of carbon fibers. ${ }^{6}$ )

As is well known, graphite is highly anisotropic in both thermal and electrical conductivity, and the TC along its basal planes is much higher than that in c-axis. However, graphite is easy to react with liquid $\mathrm{Al}$ and form $\mathrm{Al}_{4} \mathrm{C}_{3}$ phase, which can deteriorate the $\mathrm{TC}$ of $\mathrm{Al} /$ graphite composites. ${ }^{7)}$ Thus, in order to prepare $\mathrm{Al} /$ graphite composites with a preferred orientation and avoid the reactions between $\mathrm{Al}$ and graphite, powder metallurgy route is considered to be one of the effective methods to fabricate $\mathrm{Al} /$ graphite composites. As a typical technique, hot pressing has been widely studied to fabricate $\mathrm{Al} /$ graphite composites in recent years. For example, Kurita et al. ${ }^{8)}$ reported that with addition of a small

*Corresponding author, E-mail: chen@mech.tottori-u.ac.jp amount of Al-Si alloy in the Al matrix powder, an extremely high TC value of $460 \mathrm{~W} / \mathrm{mK}$ can be obtained in a fully dense hot-pressed $\mathrm{Al} / 50$ vol\% graphite sample. Chamroune et al. ${ }^{9)}$ investigated the effect of $\mathrm{Al}$ powders morphology on microstructure and $\mathrm{TC}$ of vacuum hot-pressed $\mathrm{Al} /$ graphite composites, and also obtained high TC values of 400$450 \mathrm{~W} / \mathrm{mK}$ at a graphite content of $50 \mathrm{vol} \%$. These high TC values are mainly attributed to high contents and good orientation of graphite. For example, the basal planes of the graphite are preferentially perpendicular to the hot-pressing direction. Although the hot-pressed $\mathrm{Al}$ /graphite composites showed such high TC values, their applications are still limited because hot pressing is difficult to be used in mass production.

Extrusion is a cost-effective processing technique in fabricating elongated products with various cross-sectional shapes. It can also be applied to form powders or hard-towork materials, since heavy deformation can be achieved under a high hydrostatic pressure. Furthermore, it is possible to control the preferred orientation of grains during extrusion, especially for those materials with layered structure such as graphite. However, to the best of our knowledge, no research work has been reported to fabricate $\mathrm{Al} /$ graphite composites by extrusion process.

In the present work, a hot-extrusion technique was proposed to prepare $\mathrm{Al} /$ graphite composites. The objective was to examine the effects of graphite size and content as well as extrusion temperature on extrusion behavior, microstructure, texture, and $\mathrm{TC}$ of the $\mathrm{Al} /$ graphite composites.

\section{Experimental Procedure}

Pure Al powder ( $>99.9 \%$ purity, mean particle size of $30 \mu \mathrm{m})$ and natural graphite powders with mean particle sizes of 10,60 , and $250 \mu \mathrm{m}$ were used as the starting materials, as shown in Fig. 1, the Al powder had an irregular shape, while the graphite powders exhibited either granular or flaky morphologies. In addition to these single-sized (monomodal) graphite powders, a bimodal powder, prepared from coarse 

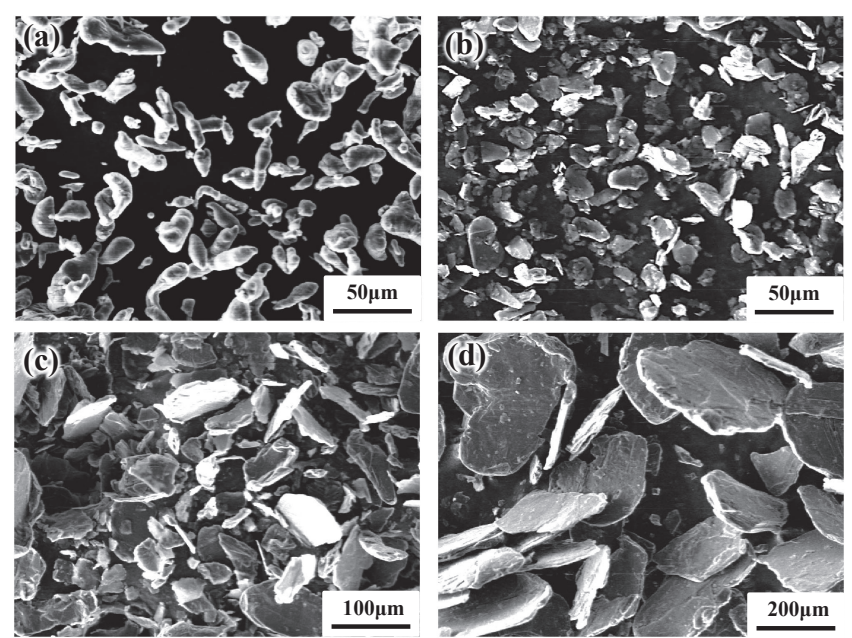

Fig. 1 SEM images of the starting materials used in the experiments. (a) Al powder $(30 \mu \mathrm{m})$ and graphite powders with mean particle sizes of (b) $10 \mu \mathrm{m}$, (c) $60 \mu \mathrm{m}$, and (d) $250 \mu \mathrm{m}$. (a)

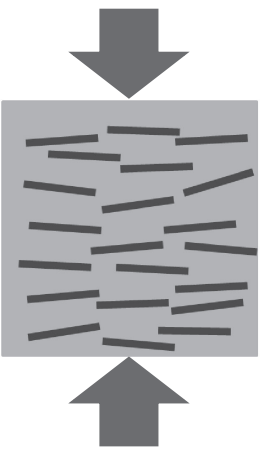

(b)

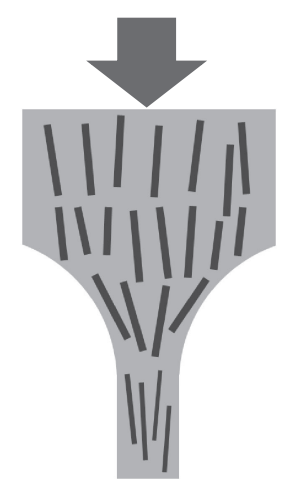

Fig. 2 Schematic views of (a) pressing and (b) extrusion of $\mathrm{Al} /$ graphite composites. The pressed green compact was rotated $90^{\circ}$ and then extruded at $450^{\circ} \mathrm{C}$.

$(250 \mu \mathrm{m})$ and fine $(10 \mu \mathrm{m})$ powders with a mixing ratio of $3: 1$, was also used for the purpose of identifying the effect of particle size distributions of graphite on extrusion behavior, microstructure, and $\mathrm{TC}$ of $\mathrm{Al} /$ graphite composites.

The $\mathrm{Al}$ and graphite powders with nominal compositions of 20,40 , and $60 \mathrm{vol} \%$ graphite were ball-milled for $12 \mathrm{~h}$ in ethanol. After drying, the $\mathrm{Al} /$ graphite powder mixture was pressed into a cylindrical green compact under a uniaxial pressure of $400 \mathrm{MPa}$, followed by vacuum-encapsulation in an $\mathrm{Al}$ can to obtain an extrusion billet. The extrusion was performed in a temperature range of $400-500^{\circ} \mathrm{C}$ with an extrusion ratio of $14: 1$ and a punch speed of $1 \mathrm{~mm} / \mathrm{min}$. Moreover, to improve the distribution and orientation of graphite in the composites and their $\mathrm{TC}$ values, some $\mathrm{Al} /$ $40 \mathrm{vol} \%$ graphite $(250 \mu \mathrm{m})$ green compacts were rotated $90^{\circ}$ (Fig. 2) and then subjected to hot extrusion at $450^{\circ} \mathrm{C}$.

The density of the extruded samples was determined by the Archimedes method. Phase identification was performed by $\mathrm{X}$-ray diffraction (XRD) with $\mathrm{Cu} \mathrm{K} \alpha$ radiation. The microstructure was observed by scanning electron microscopy (SEM). Orientation imaging microscopy (OIM) analysis was performed using SEM equipped with an electron backscattered diffraction (EBSD) system. The TC was determined by measuring thermal diffusivity and specific heat at room

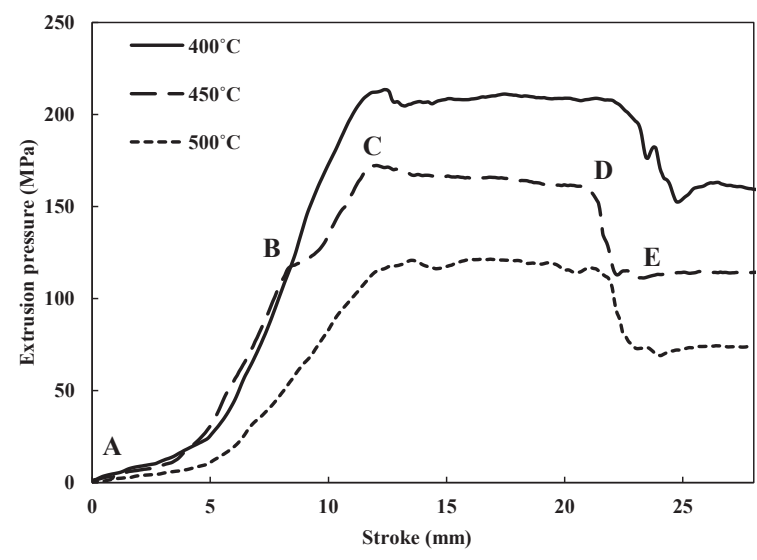

Fig. 3 Extrusion pressure-stroke curves of $\mathrm{Al} / 40$ vol\% graphite $(250 \mu \mathrm{m})$ samples extruded at different temperatures.

temperature by using a laser flash apparatus (LFA457 Micro Flash, Netzsch, Germany).

The orientation degree of the graphite in the extruded samples was estimated using the Lotgering method ${ }^{10)}$ by the following equation:

$$
\begin{gathered}
f=\left(P-P_{0}\right) /\left(1-P_{0}\right) \\
P_{0}=\sum I_{0}(00 l) / \sum I_{0}(h k l) \\
P=\sum I(00 l) / \sum I(h k l)
\end{gathered}
$$

where $f$ is orientation factor; $P_{0}$ and $P$ are the ratios of the integrated intensities of all $(00 l)$ planes to those of all $(h k l)$ planes for randomly and preferentially oriented samples, respectively. The value of $f$ varies between 0 and 1 , where $f=0$ corresponds to random orientation, while $f=1$ corresponds to perfect orientation.

\section{Results and Discussion}

\subsection{Extrusion behavior}

Figure 3 shows the extrusion pressure vs. stroke curves of $\mathrm{Al} / 40$ vol\% graphite $(250 \mu \mathrm{m})$ samples extruded at different temperatures. In the initial stage up to point B shown in Fig. 3, the pressure gradually increased with extrusion stroke. This corresponds to the compaction of $\mathrm{Al} /$ graphite powder inside the $\mathrm{Al}$ can and plastic deformation of the $\mathrm{Al}$ can. At point B where the slope of the pressure vs. stroke curve became small, the $\mathrm{Al}$ in the front end of the billet started to be extruded out of the die. When the pressure reached point $\mathrm{C}$, $\mathrm{Al} /$ graphite composite started to be formed with $\mathrm{Al}$ sheath on its surface layer. As the extrusion proceeded, the change of the pressure was not evident and the extrusion of the composite steadily continued up to point $\mathrm{D}$. After the $\mathrm{Al} /$ graphite compact was completely extruded out of the die, only the residual $\mathrm{Al}$ sheath was subjected to the extrusion and thus the pressure level was sharply decreased (point $\mathrm{E}$ as shown in Fig. 3). In addition, as the extrusion temperature increased, the extrusion pressure level decreased due to lower deformation resistance at a higher extrusion temperature.

Similar extrusion behavior was also found in the extrusion of the samples with different graphite sizes and contents. The effect of graphite content on extrusion pressure level was not 


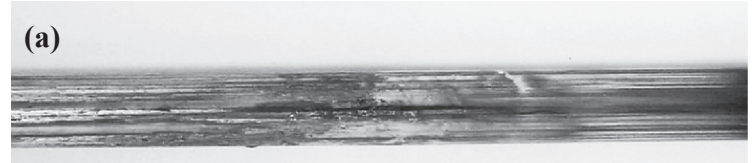

(b)

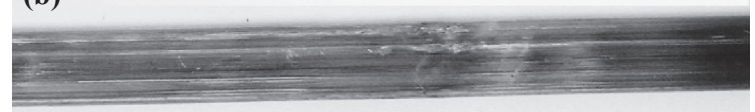

(c)

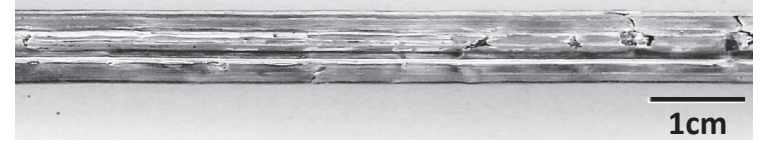

Fig. 4 Appearances of $\mathrm{Al} /$ graphite samples with (a) $20 \mathrm{vol} \%$, (b) $40 \mathrm{vol} \%$, and (c) $60 \mathrm{vol} \%$ graphite $(250 \mu \mathrm{m})$. Extrusion temperature: $450^{\circ} \mathrm{C}$.

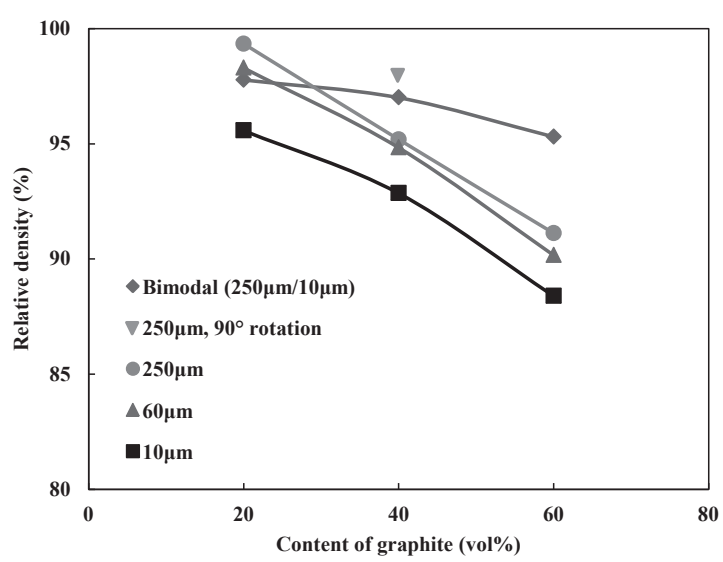

Fig. 5 Variations of the relative density on graphite content for $\mathrm{Al} /$ graphite samples extruded at $450^{\circ} \mathrm{C}$

remarkable. However, with the decrease in graphite size, the extrusion pressure level increased, which may result from the increased $\mathrm{Al} /$ graphite interfaces and thus result in higher deformation resistance.

Figure 4 shows the appearances of the extruded $\mathrm{Al} /$ graphite $(250 \mu \mathrm{m})$ samples with different graphite contents. The samples with lower graphite contents $(20 \mathrm{vol} \%$ and $40 \mathrm{vol} \%$ ) exhibited sound appearances, and no evident cracks, voids and other defects were observed, as shown in Fig. 4(a) and (b). However, many defects were clearly observed on the surface of the sample with 60 vol\% graphite (Fig. 4(c)). This may result from severe aggregation of graphite due to a large amount of graphite and thus lead to poor formability. In addition, it has been confirmed that graphite size and extrusion temperature have a small effect on appearances of the extruded samples under the experimental conditions used in the current work. These results suggest that graphite content is a major factor influencing the formability of $\mathrm{Al} /$ graphite composites in the extrusion temperature range of $400-500^{\circ} \mathrm{C}$.

Figure 5 shows the variations of relative density of the hotextruded $\mathrm{Al}$ /graphite samples with different graphite particle sizes and contents. The relative density of all the samples decreased with increasing the graphite content. This indicates that the presence of graphite inhibits the deformation of Al matrix and densification of the composites. For the monomodal graphite powders, as the particle size of graphite increased, the relative density became higher. It is believed that with the incorporation of larger graphite particles, the interfacial area between graphite and Al particles decreases. This results in a smaller inhibition effect of graphite on densification of the Al matrix during hot extrusion. Therefore, the extruded samples with larger graphite sizes showed higher density values, as shown in Fig. 5.

On the other hand, the $90^{\circ}$-rotated sample showed higher density value compared to the non-rotated sample. As illustrated in Fig. 2, the graphite flakes tend to be arranged in the direction perpendicular to the loading direction during pressing of $\mathrm{Al} /$ graphite powder mixture. After $90^{\circ}$ rotation, further deformation of graphite along the extrusion direction occurs easily during subsequent hot-extrusion process. This is because the graphite distributions in the $90^{\circ}$-rotated billet are approximately parallel to the extrusion direction, which is also beneficial to reduction in breakage of graphite during the extrusion. These lead to enhancement in densification of the extruded sample.

With regard to the bimodal samples containing both $250 \mu \mathrm{m}$ and $10 \mu \mathrm{m}$ graphite powders, the relative density of the extruded samples did not decrease as remarkably as those of the monomodal samples and exhibited higher values at graphite contents of 40 and $60 \mathrm{vol} \%$ (Fig. 5). It has been demonstrated that when the size ratio and volume fraction ratio of large to small particles reach certain values, respectively, the voids in mixed-sized sample can be obviously reduced compared to the single-sized samples, ${ }^{11)}$ thus leading to increase in relative density. Similar improvements in density have also been found in $\mathrm{Al} / \mathrm{SiC}$ composites with mixed-sized SiC particles. ${ }^{12}$ )

\subsection{Microstructure and texture}

Figure 6 shows the SEM images (backscattered electron mode) on longitudinal sections of the monomodal samples with different graphite sizes and contents, where the white and dark regions correspond to $\mathrm{Al}$ and graphite, respectively. It was clearly observed that the graphite tended to be distributed along the extrusion direction in the extruded samples. This tendency seems to be weakened and the thickness of the deformed graphite became larger with increasing graphite content, which is attributed to aggregation of graphite. The preferred orientation of graphite along the extrusion direction in hot-extruded samples is believed to be associated with the shear deformation occurred during the extrusion, because graphite can be easily deformed along the basal plane due to its layered structure. In addition, as the graphite size decreased, both the length and thickness of the deformed graphite were reduced, and the graphite showed more homogeneous distributions within the $\mathrm{Al}$ matrix. In the case of the graphite particles with an average size of $10 \mu \mathrm{m}$, when the graphite content attained 60 vol\% (Fig. 6(i)), it appears that the $\mathrm{Al}$ with a bright contrast is homogeneously distributed in the graphite matrix.

Figure 7 shows the SEM images on longitudinal sections of the bimodal samples with different graphite contents. Similar to the monomodal samples, the graphite was also distributed along the extrusion direction, and smaller graphite particles were uniformly dispersed in the Al matrix. With 


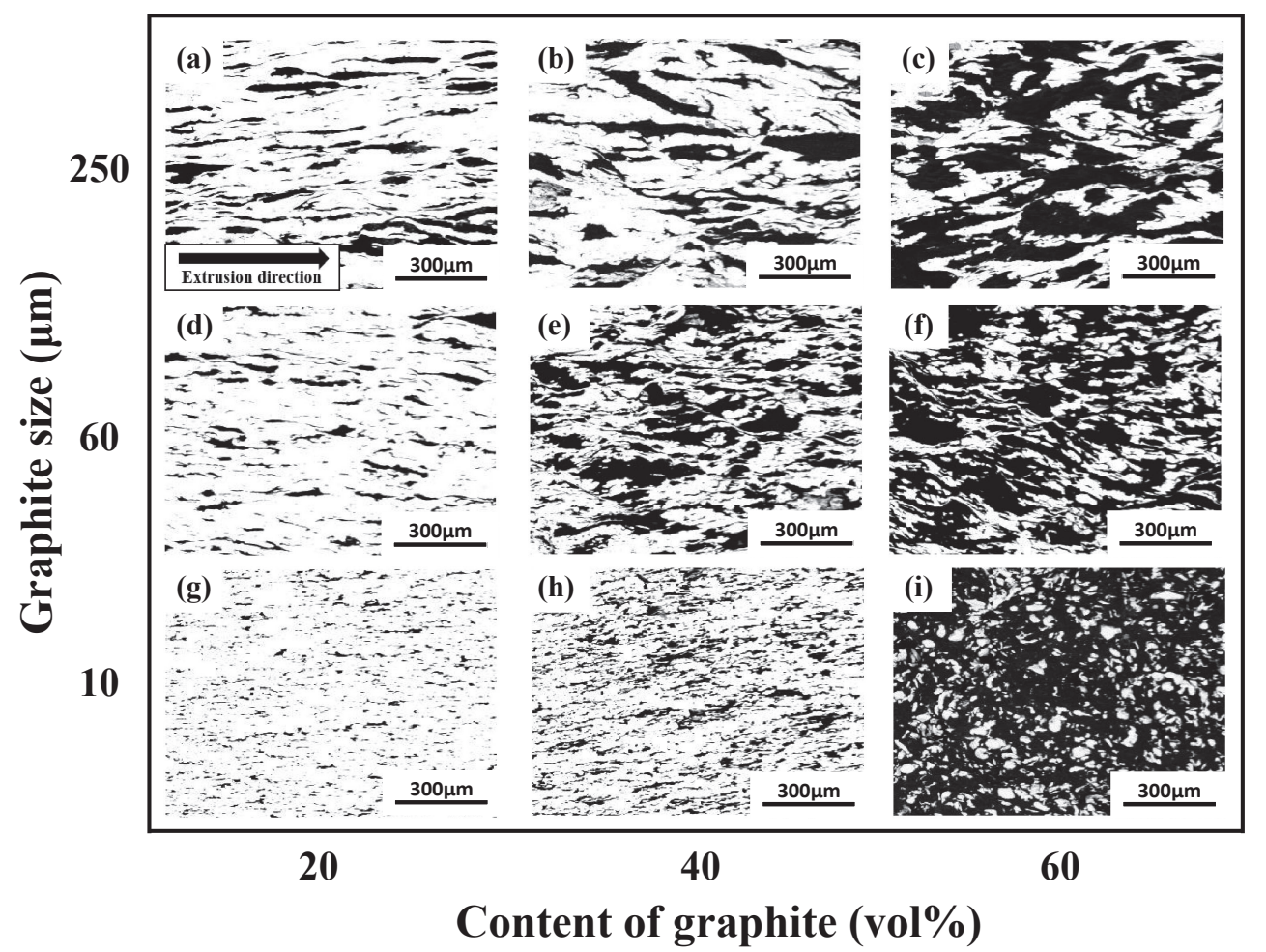

Fig. 6 SEM images on longitudinal sections of the hot-extruded monomodal samples with different graphite sizes and contents. Extrusion temperature: $450^{\circ} \mathrm{C}$.
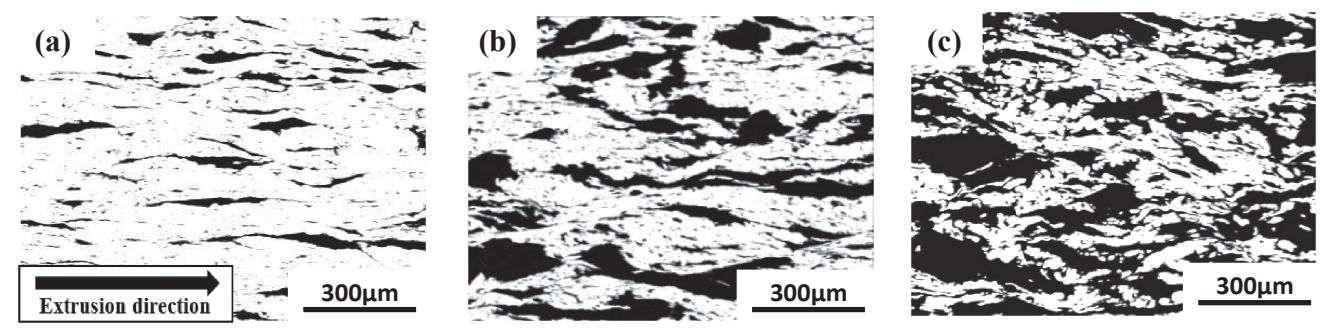

Fig. 7 SEM images on longitudinal sections of the hot-extruded bimodal samples with graphite content of (a) 20 vol $\%$, (b) 40 vol $\%$, and (c) 60 vol\%. Extrusion temperature: $450^{\circ} \mathrm{C}$.

increasing the graphite content, more aggregation of graphite can also be observed in the hot-extruded samples. Since the average particle size $(10 \mu \mathrm{m})$ of the small graphite powder is much smaller than those of both $\mathrm{Al}(30 \mu \mathrm{m})$ and large graphite powder $(250 \mu \mathrm{m})$, it is assumed that the small graphite particles can effectively fill up the voids between $\mathrm{Al} / \mathrm{Al}, \mathrm{Al} /$ large graphite, and large graphite/graphite particles in the bimodal samples, thus resulting in higher relative density (Fig. 5).

Figure 8(a)-(c) shows the SEM images of the Al/40 vol\% graphite $(250 \mu \mathrm{m})$ samples extruded at different temperatures. It seems that the majority of graphite are distributed along the extrusion direction at $400^{\circ} \mathrm{C}$. With increasing the extrusion temperature, the aspect ratio of the graphite became smaller and its distribution along the extrusion direction became weaker. It has been reported that the mechanical properties of graphite are almost unchanged under $1000^{\circ} \mathrm{C},{ }^{13)}$ while the deformation resistance of $\mathrm{Al}$ rapidly decreases with increasing temperature, which can be easily found from the pressure levels after point $\mathrm{E}$ at different temperatures shown (a) 5
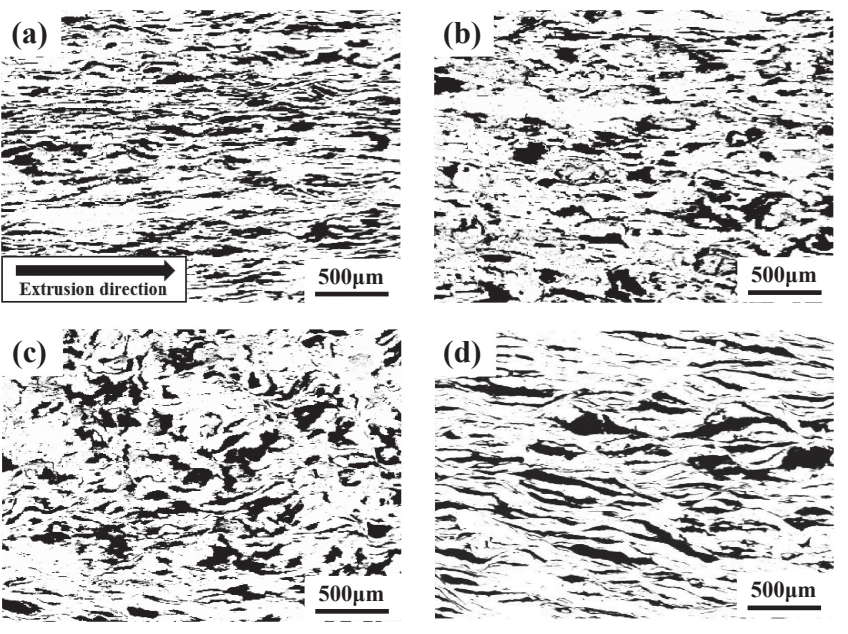

Fig. 8 SEM images on longitudinal sections of $\mathrm{Al} / 40 \mathrm{vol} \%$ graphite $(250 \mu \mathrm{m})$ samples extruded at (a) $400^{\circ} \mathrm{C}$, (b) $450^{\circ} \mathrm{C}$, (c) $500^{\circ} \mathrm{C}$, and (d) $450^{\circ} \mathrm{C}\left(90^{\circ}\right.$-rotated sample) 


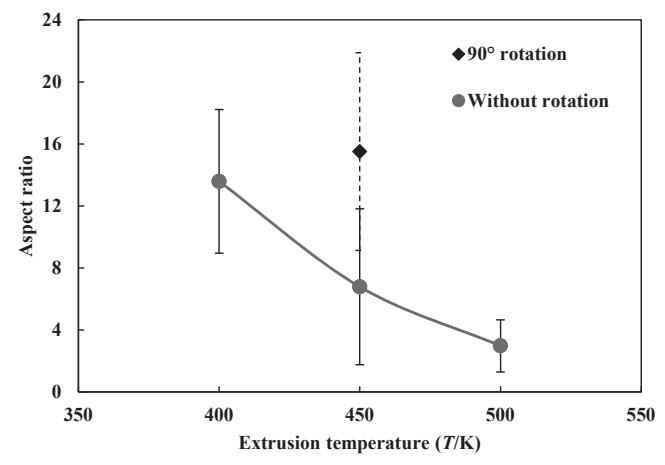

Fig. 9 Measured aspect ratios of graphite in $\mathrm{Al} / 40 \mathrm{vol} \%$ graphite $(250 \mu \mathrm{m})$ samples with and without billet rotation.

in Fig. 3. Therefore, the changes in morphology and distribution of the graphite in $\mathrm{Al} /$ graphite composites with extrusion temperature are likely to be due to the difference in deformation resistance between $\mathrm{Al}$ and graphite. As the extrusion temperature increases, the deformation of the $\mathrm{Al}$ matrix occurs easily compared to graphite. As a result, the deformed graphite flakes exhibited smaller aspect ratios at a higher temperature.

Figure $8(d)$ shows the SEM image on the longitudinal section of the $90^{\circ}$-rotated $\mathrm{Al} / 40$ vol\% graphite $(250 \mu \mathrm{m})$ sample. In comparison with the non-rotated sample shown in Fig. 8(b), it is obvious that the distribution of graphite along the extrusion direction became stronger in the $90^{\circ}$-rotated sample. Furthermore, the breakage of graphite was reduced evidently, which led to fewer $\mathrm{Al} /$ graphite interfaces.

Figure 9 illustrates the quantitative results of the aspect ratios of graphite in $\mathrm{Al} / 40 \mathrm{vol} \%$ graphite $(250 \mu \mathrm{m})$ samples, which were measured from the SEM images. With increasing the extrusion temperature, the average aspect ratio of graphite decreased from about 13 to 4 . In addition, the aspect ratio of the $90^{\circ}$-rotated sample showed a higher value of about 16 than the non-rotated sample at an extrusion temperature of $450^{\circ} \mathrm{C}$, revealing the effectiveness of pressed compact rotation on improving the orientation of graphite in $\mathrm{Al} /$ graphite composites.

The effect of extrusion temperature on the microstructure of hot-extruded $\mathrm{Al} / 40 \mathrm{vol} \%$ graphite samples was also examined by EBSD. Figure 10 shows the inverse pole figure (IPF) maps of Al matrix on longitudinal sections of the composites extruded at different temperatures. It should be noted that the dark regions in Fig. 10 correspond to graphite and its IPF maps are not included in the figure because the confidence index (CI) values of graphite are very small. The extremely small CI value of the graphite may be associated with its uneven surfaces in polished $\mathrm{Al} /$ graphite samples because $\mathrm{Al}$ and graphite have different hardness values and graphite easily drops out during polishing. All the maps in Fig. 10 have CI values of $>0.1$, suggesting that the IPF maps shown in Fig. 10 represent the orientations of the $\mathrm{Al}$ matrix. ${ }^{14,15)}$

As shown in Fig. 10, most of the Al grains were elongated along the extrusion direction in the extruded samples. As the extrusion temperature increased, grain growth occurred. The average grain sizes of the $\mathrm{Al}$ matrix were measured as $9.79 \mu \mathrm{m}, 10.96 \mu \mathrm{m}$, and $11.36 \mu \mathrm{m}$ at $400^{\circ} \mathrm{C}, 450^{\circ} \mathrm{C}$, and
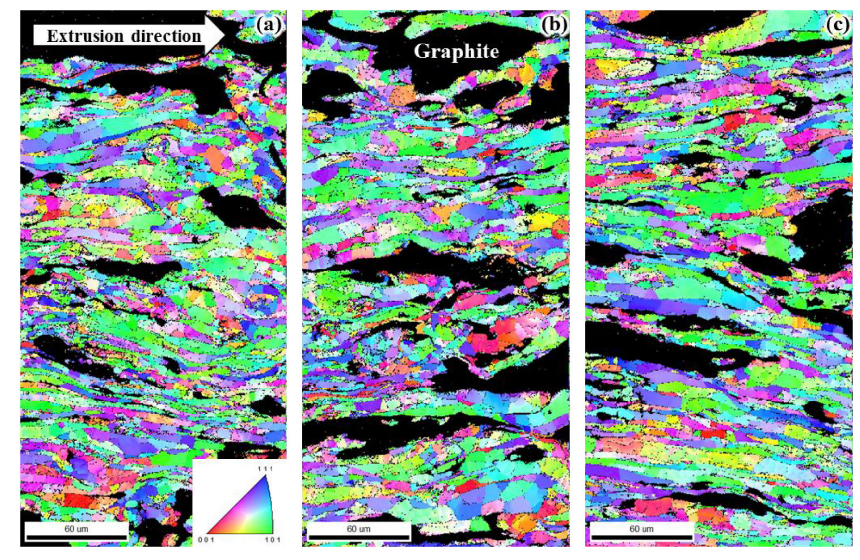

Fig. 10 Inverse pole figure (IPF) maps on longitudinal sections of $\mathrm{Al} /$ 40 vol\% graphite $(250 \mu \mathrm{m})$ samples extruded at (a) $400^{\circ} \mathrm{C}$, (b) $450^{\circ} \mathrm{C}$, and (c) $500^{\circ} \mathrm{C}$. (a)

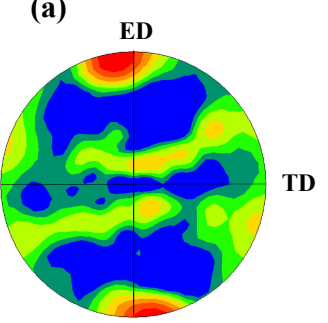

(b)

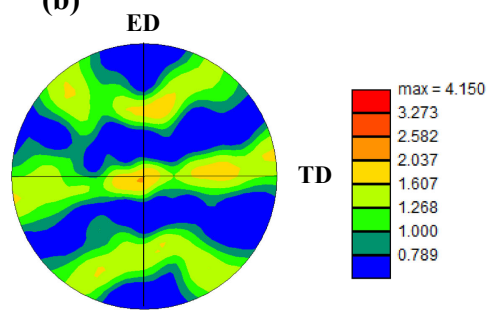

Fig. 11 (a) $\{111\}$ and (b) $\{101\}$ pole figures on longitudinal sections of the $450^{\circ} \mathrm{C}$-extruded $\mathrm{Al} / 40$ vol $\%$ graphite $(250 \mu \mathrm{m})$ sample.

$500^{\circ} \mathrm{C}$, respectively. In addition, from the IPF maps shown in Fig. 10, one of the main textures of the $\mathrm{Al}$ matrix on longitudinal sections arises from $\{111\}$, which is in agreement with the texture of hot-extruded commercial pure $\mathrm{Al}$ as reported by Bieda et al. ${ }^{16)}$ However, in addition to $\{111\}$, the IPF maps of $\mathrm{Al}$ in the hot-extruded $\mathrm{Al} /$ graphite composites in the present study showed other textures such as $\{101\}$ and $\{001\}$. This is considered to be attributed to two reasons: (i) the existence of graphite limits the deformation and rotation of $\mathrm{Al}$ grains during hot extrusion, and (ii) some original $\{111\}\langle 110\rangle$ slip systems may be replaced by $\{101\}\langle 110\rangle$ under the conditions of high strain rates. ${ }^{17)}$

To further examine the textures of the Al matrix, the $\{111\}$ and $\{101\}$ pole figures on longitudinal sections of the $450^{\circ} \mathrm{C}$ extruded samples are shown in Fig. 11. From the $\{111\}$ pole figure, it is clear that the positions of two strong pole intensities fitted well with the extrusion direction. Furthermore, the $\{101\}$ pole figure exhibited a typical pole figure as seen in a $\{111\}$ fiber texture. ${ }^{16)}$ This demonstrates again that the Al matrix showed $\{111\}$ texture on the longitudinal sections of the extruded samples.

As an example, Fig. 12(a) illustrates the XRD patterns on longitudinal and transverse sections of $\mathrm{Al} / 40 \mathrm{vol} \%$ graphite samples extruded at $450^{\circ} \mathrm{C}$ and $500^{\circ} \mathrm{C}$. The two patterns on longitudinal sections at $450^{\circ} \mathrm{C}$ and $500^{\circ} \mathrm{C}$ are similar to each other, where the $(00 l)$ basal planes of graphite (e.g., (002) and (004)) as well as (111) peak of Al showed large diffraction intensities on the sections parallel to the extrusion direction. Furthermore, in comparison with the patterns on longitudinal sections, the pattern on transverse section showed weaker diffraction intensities on $(00 l)$ basal planes of graphite and 

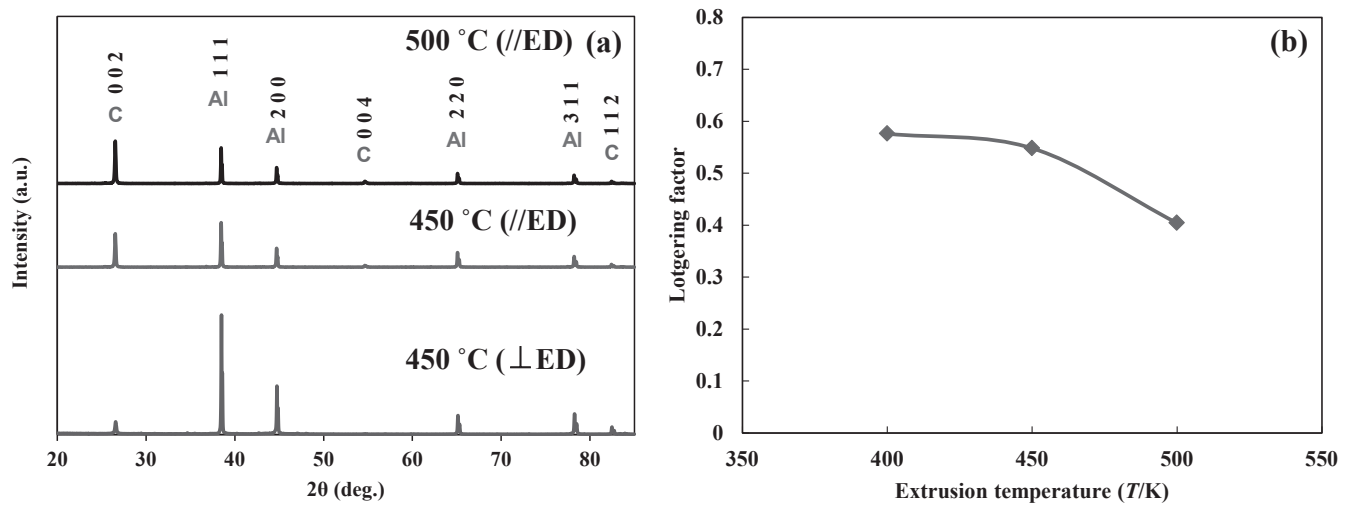

Fig. 12 (a) XRD patterns on longitudinal sections and transverse section of $\mathrm{Al} / 40$ vol\% graphite $(250 \mu \mathrm{m})$ samples extruded at $450^{\circ} \mathrm{C}$ and $500^{\circ} \mathrm{C}(\mathrm{b})$ dependence of the Lotgering factor on extrusion temperature.
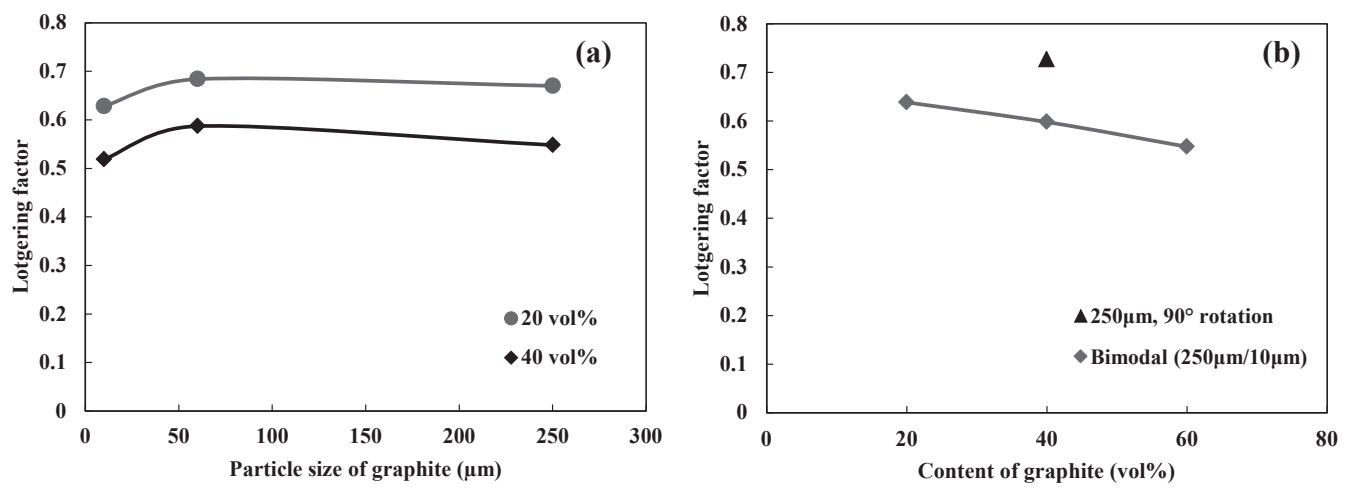

Fig. 13 Dependences of the Lotgering factor on (a) graphite content and particle size and (b) graphite content in the bimodal and $90^{\circ}$ rotated samples.

stronger diffraction intensities of $\mathrm{Al}$, especially on (111) plane. These results further suggest that the $(00 l)$ basal planes of graphite are preferentially orientated to the extrusion direction in hot-extruded $\mathrm{Al} /$ graphite composites. Besides, no peaks of aluminum carbide $\left(\mathrm{Al}_{4} \mathrm{C}_{3}\right)$ phase were detected in the extruded samples, but further detailed TEM observations at $\mathrm{Al} /$ graphite interfaces are necessary.

In order to quantitatively evaluate the orientation degree of the graphite in hot-extruded $\mathrm{Al} / 40 \mathrm{vol} \%$ graphite samples, the orientation factor $f_{(00)}$ of the graphite was calculated by the Lotgering method from the XRD data, and the dependence of the Lotgering factor on extrusion temperature is shown in Fig. 12(b). With the increase in extrusion temperature, the Lotgering factor slightly decreased from $400^{\circ} \mathrm{C}$ to $450^{\circ} \mathrm{C}$, and then obviously decreased from $450^{\circ} \mathrm{C}$ to $500^{\circ} \mathrm{C}$. The orientation evolution of the graphite is in good agreement with the graphite distributions along the extrusion direction shown in Fig. 8(a)-(c).

Figure 13(a) shows the dependence of the Lotgering factor on graphite content and size. The extruded samples with a larger content of graphite exhibited smaller values of the Lotgering factor. It is considered that the severe aggregation of graphite at a larger content (Fig. 6) decreases the deformation degree of graphite along the basal plane. On the other hand, when the graphite particle size was increased from 10 to $60 \mu \mathrm{m}$, the Lotgering factor increased slightly. This indicates that small-sized graphite particles are somewhat difficult to be deformed along the basal planes during extrusion compared to large-sized graphite. However, as the graphite particle size was further increased from 60 to $250 \mu \mathrm{m}$, the Lotgering factor remained almost unchanged. These results suggest that the particle size of graphite has a small influence on the orientation degree of the graphite in the extruded $\mathrm{Al} /$ graphite composites.

The dependence of the Lotgering factor on graphite content in the bimodal and $90^{\circ}$-rotated samples is illustrated in Fig. 13(b). Similar to the monomodal samples shown in Fig. 13(a), the bimodal samples showed a gradually reduced trend in the Lotgering factor with increasing the graphite content due to the aggregation of graphite. For the $90^{\circ}-$ rotated sample, its Lotgering factor exhibited a higher value than the sample without rotation. This result indicates that the $90^{\circ}$-rotation of the pressed green compact can promote the shear deformation and preferred orientation of the graphite during hot-extrusion process (Fig. 2).

\subsection{Thermal conductivity}

Figure 14 shows the thermal conductivity (TC) of hotextruded $\mathrm{Al} / 40 \mathrm{vol} \%$ graphite samples as a function of extrusion temperature. It is worth pointing out that the measuring direction of both thermal diffusivity and specific heat was parallel to the extrusion direction. As a reference, the TC value of a $450^{\circ} \mathrm{C}$-extruded pure $\mathrm{Al}$ sample was also plotted in Fig. 14. The TC value increased as the extrusion temperature increased from 400 to $450^{\circ} \mathrm{C}$. This is mainly attributed to the grain growth (Fig. 10) at a higher extrusion temperature, which causes reduction in scattering of phonons at grain boundaries. However, as the extrusion temperature 


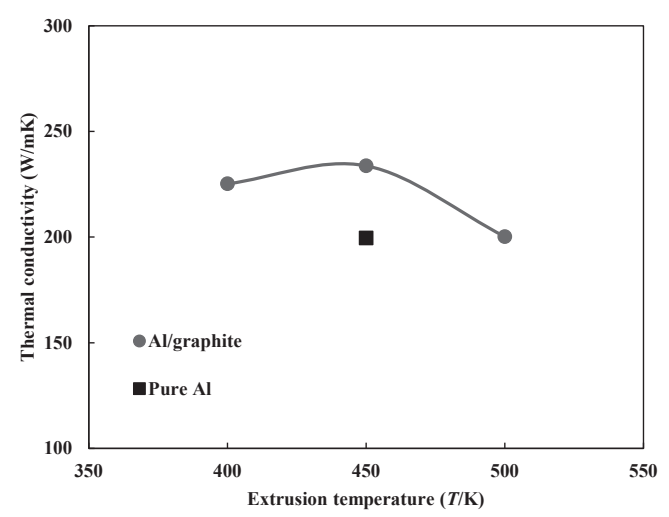

Fig. 14 Thermal conductivity of $\mathrm{Al} / 40 \mathrm{vol} \%$ graphite $(250 \mu \mathrm{m})$ samples as a function of extrusion temperature.

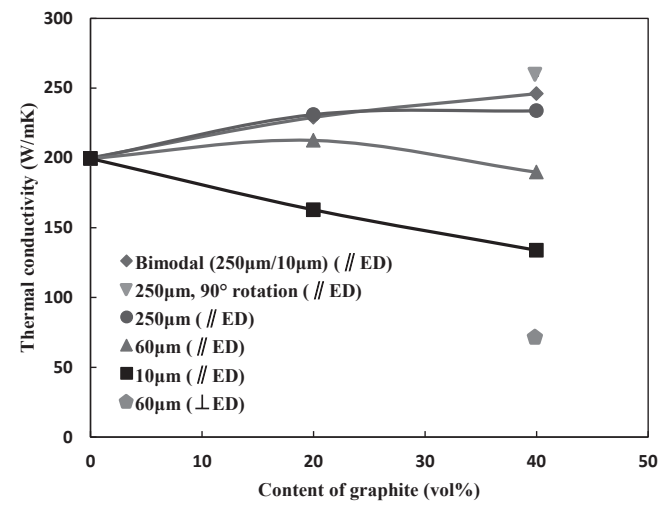

Fig. 15 Thermal conductivity of $\mathrm{Al} /$ graphite composites extruded at $450^{\circ} \mathrm{C}$.

further increased from 450 to $500^{\circ} \mathrm{C}$, the $\mathrm{TC}$ decreased and thus reached a peak at $450^{\circ} \mathrm{C}$. A lower $\mathrm{TC}$ value at $500^{\circ} \mathrm{C}$ is likely to be due to a significant reduction in orientation degree of graphite as mentioned previously (Fig. 12(b)). Another possible reason is the formation of $\mathrm{Al}_{4} \mathrm{C}_{3}$ compound during the hot extrusion at $500^{\circ} \mathrm{C}$ although $\mathrm{Al}_{4} \mathrm{C}_{3}$ cannot be detected in XRD analysis. The above results suggest that grain boundaries play a dominant role in thermal conduction in the extrusion temperature range of $400-450^{\circ} \mathrm{C}$, whereas the orientation degree of the graphite becomes dominant at $450-500^{\circ} \mathrm{C}$.

Figure 15 shows the graphite content dependence of TC of the monomodal, bimodal, and $90^{\circ}$-rotated samples extruded at $450^{\circ} \mathrm{C}$. For the samples with the monomodal graphite powders, as the graphite content increased, the TC increased gradually in $\mathrm{Al} /$ graphite $(250 \mu \mathrm{m})$ samples, whereas the TC had small change in $\mathrm{Al} /$ graphite $(60 \mu \mathrm{m})$ samples and decreased in $\mathrm{Al} /$ graphite $(10 \mu \mathrm{m})$ samples. Generally, a larger graphite content leads to a higher TC value as indicated in $\mathrm{Al} /$ graphite $(250 \mu \mathrm{m})$ samples in this work. The reductions in TC with increasing graphite content in $10 \mu \mathrm{m}$ - and $60 \mu \mathrm{m}$ graphite incorporated samples are mainly associated with lower relative density of the composites (Fig. 5) and larger interfacial thermal resistance due to smaller sizes of the graphite particles.

As is well known, thermal conduction in metals is mainly dominated by diffusion and collisions of electrons, while that in nonmetals depends to a large extent on propagation and collisions of phonons. Accordingly, energy transfer must occur between electrons and phonons across metal/nonmetal interfaces. Majumder et al. ${ }^{18)}$ have proposed two possible heat transport pathways at the metal/nonmetal interfaces: (i) coupling between electrons in the metal and phonons in the nonmetal through an harmonic interactions, and (ii) coupling between electrons and phonons within the metal in vicinity to the interfaces, and subsequent coupling between phonons in the metal and phonons in the nonmetal. In the present study, since the electron-phonon interactions in $\mathrm{Al}$ are extremely weak, ${ }^{19)}$ the heat transfer across $\mathrm{Al} /$ graphite interfaces is presumably attributed to the coupling between electrons and phonons near the interfaces in the $\mathrm{Al}$ matrix and subsequent coupling between phonons in the $\mathrm{Al}$ and phonons in the graphite. Accordingly, the intrinsic thermal resistance arising from electron-phonon coupling losses in the Al matrix and the thermal boundary resistance coming from phononphonon coupling losses at $\mathrm{Al} /$ graphite interfaces constitute the $\mathrm{Al} /$ graphite interfacial thermal resistance, ${ }^{20,21)}$ which inhibits thermal conduction in the $\mathrm{Al} /$ graphite composites. Furthermore, Luo et al. ${ }^{22}$ ) have reported that the effects of phonon-defect and phonon-interface interactions at carbon/ carbon interfaces can lead to reduction of phonon mean free path. In the same way, it is believed that the graphite/graphite interfaces can also act as an inhibitor of the thermal conduction. Consequently, at a higher graphite content and a smaller graphite size, in addition to the effect of lower density, the existence of more $\mathrm{Al} /$ graphite interfaces and graphite/graphite interfaces also leads to reduction in TC, as shown in Fig. 15.

With regard to the bimodal samples, the TC increased with increasing graphite content and exhibited a higher value at $40 \mathrm{vol} \%$ compared to those of the monomodal samples. Although the small graphite particles with an average size of $10 \mu \mathrm{m}$ result in more $\mathrm{Al} /$ graphite interfaces and graphite/ graphite interfaces in the bimodal samples, the improvement in TC is believed to mainly arise from the significant increase in relative density (Fig. 5).

As for the $90^{\circ}$-rotated $\mathrm{Al} / 40 \mathrm{vol} \%$ graphite $(250 \mu \mathrm{m})$ sample, a higher TC value was obtained in comparison with the sample with exactly the same composition but without rotation. Such an enhancement in TC is considered to be associated with its higher relative density, fewer $\mathrm{Al} /$ graphite and graphite/graphite interfaces as well as higher orientation degree $f_{(00 l)}$ of the graphite as mentioned above.

On the other hand, the TC in the direction perpendicular to the extrusion direction was also measured. The results indicated that the TC values in the direction parallel to extrusion direction (//ED) were much larger than those perpendicular to the extrusion direction $(\perp E D)$. For example, for $\mathrm{Al} / 40 \mathrm{vol} \%$ graphite $(60 \mu \mathrm{m})$ sample, the TC parallel to the extrusion direction was 2.6 times larger than that perpendicular to the extrusion direction.

From the above results, it can be found that the hotextruded $\mathrm{Al} /$ graphite composites exhibited relatively lower TC in comparison with the hot-pressed samples. This is presumably attributed to larger interfacial thermal resistance, because the deformation and breakage of graphite flakes occur during hot extrusion, resulting in larger $\mathrm{Al} /$ graphite interfaces. Nevertheless, the hot-extruded $\mathrm{Al}$ /graphite composites showed excellent workability and remarkable anisotropic 
behavior in TC. Furthermore, we have attempted to reduce $\mathrm{Al}$ /graphite interfacial thermal resistance and improve the density of the composites, which result in a significant enhancement in TC of the extruded $\mathrm{Al} /$ graphite composites (these results will be reported elsewhere). Accordingly, hotextrusion process is believed to be a promising technique to fabricate $\mathrm{Al} /$ graphite composites for thermal management applications. Moreover, further studies on the coefficient of thermal expansion and mechanical properties of the extruded $\mathrm{Al}$ /graphite composites are in progress.

\section{Conclusions}

Sound and dense $\mathrm{Al} /$ graphite composites with relative density of $>95 \%$ were successfully fabricated by a hotextrusion process under the conditions of extrusion temperatures ranging from $400^{\circ} \mathrm{C}$ to $500^{\circ} \mathrm{C}$ and graphite contents of $\leq 40 \mathrm{vol} \%$. The morphology and distribution of the graphite in extruded $\mathrm{Al} /$ graphite composites depend to a large extent on the deformation resistances of both $\mathrm{Al}$ and graphite. The microstructural observations showed that graphite was mainly distributed along the extrusion direction. As the extrusion temperature increased, the aspect ratio of the graphite became smaller and its distribution along the extrusion direction became weaker. The $(00 l)$ basal planes of the graphite in extruded composites exhibited preferred orientation on longitudinal sections parallel to the extrusion direction. The orientation degree of graphite decreased with increasing graphite content and extrusion temperature, but it had a small change when varying graphite size.

The preferred orientation of graphite resulted in an anisotropy of TC in the extruded samples. The TC in the extrusion direction was higher than that in the direction perpendicular to the extrusion direction. In addition, the incorporation of large-sized graphite flakes is beneficial to the improvement in $\mathrm{TC}$ of extruded $\mathrm{Al} /$ graphite composites. In comparison with monomodal graphite powder, the utilization of bimodal graphite powder is beneficial to the enhancement of both relative density and $\mathrm{TC}$ of the $\mathrm{Al} /$ graphite composites, although the incorporation of small graphite particles causes more $\mathrm{Al} /$ graphite interfaces. Moreover, the $90^{\circ}$-rotated sample exhibited higher TC $(259 \mathrm{~W} / \mathrm{mK})$ due to its higher relative density, fewer $\mathrm{Al} /$ graphite interfaces, and higher orientation degree of the graphite.

\section{Acknowledgments}

This work was supported in part by the Light Metal Educational Foundation, Japan. The authors would like to thank T. Yoshioka and T. Harada of Shimane Institute for Industrial Technology as well as Prof. S. Morito of Shimane University for their experimental supports and fruitful discussion.

\section{REFERENCES}

1) C. Zweben: JOM 50 (1998) 47-51.

2) A. Luedtke: Adv. Eng. Mater. 6 (2004) 142-144.

3) S. Mallik, N. Ekere, C. Best and R. Bhatti: Appl. Therm. Eng. 31 (2011) 355-362.

4) J.M. Molina, J. Narciso, L. Weber, A. Mortensen and E. Louis: Mater. Sci. Eng. A 480 (2008) 483-488.

5) K. Mizuuchi, K. Inoue, Y. Agari, Y. Morisada, M. Sugioka, M. Tanaka, T. Takeuchi, J.I. Tani, M. Kawahara and Y. Makino: Compos., Part B 42 (2011) 825-831.

6) T.T. Liu, X.B. He, Q. Liu, S.B. Ren, Q.P. Kang, L. Zhang and X.H. Qu: J. Mater. Sci. 49 (2014) 6705-6715.

7) T. Etter, P. Schulz, M. Weber, J. Metz, M. Wimmler, J.F. Loffler and P.J. Uggowitzer: Mater. Sci. Eng. A 448 (2007) 1-6.

8) H. Kurita, T. Miyazaki, A. Kawasaki, Y.F. Lu and J.F. Silvain: Compos., Part A 73 (2015) 125-131.

9) N. Chamroune, D. Mereib, F. Delange, N. Caillault, Y.F. Lu, J.L. Grosseau-Poussard and J.F. Silvain: J. Mater. Sci. 53 (2018) 81808192.

10) F.K. Lotgering: J. Inorg. Nucl. Chem. 9 (1959) 113-123.

11) A.B. Yu, N. Standish and A. McLean: J. Am. Ceram. Soc. 76 (1993) 2813-2816.

12) J.M. Molina, S. Arunachalam, R. Arpon and J. Narciso: Acta Mater. 50 (2002) 247-257.

13) D.P. Kim, Y. Suhng and M.M. Labes: Carbon 30 (1992) 729-737.

14) D.P. Field: Ultramicroscopy 67 (1997) 1-9.

15) Z.L. Wang, T. Akao, T. Onda and Z.C. Chen: Scr. Mater. 136 (2017) 111-114.

16) M. Bieda, S. Boczkal, P. Koprowski, K. Sztwiertnia and K. Piela: Arch. Metall. Mater. 61 (2016) 461-468.

17) X. Jiang, M. Galano and F. Audebert: Mater. Charact. 88 (2014) 111118.

18) A. Majumdar and P. Reddy: Appl. Phys. Lett. 84 (2004) 4768-4770.

19) M.L. Huberman and A.W. Overhauser: Phys. Rev. B 50 (1994) 28652873.

20) W.J. Li, Y. Liu and G.H. Wu: Carbon 95 (2015) 545-551.

21) M. Battabyal, O. Beffort, S. Kleiner, S. Vaucher and L. Rohr: Diam. Relat. Mater. 17 (2008) 1438-1442.

22) R.Y. Luo, T. Liu, J.S. Li, H.B. Zhang, Z.J. Chen and G.L. Tian: Carbon 42 (2004) 2887-2895. 